\title{
On the Potential Effect of Increased Dietary Intake of Fruits and Vegetables on Biomarkers of Lipid Peroxidation in Type 2 Diabetes Patients
}

\author{
J. Pincemail ${ }^{1 \mathrm{a},{ }^{*}}$, N. Paquot $^{1 \mathrm{~b}}$, J. Cillard ${ }^{2}$, I. Hininger ${ }^{3}$, L. Iuliano ${ }^{4}$, M. Cazaubiel $^{5}$, \\ F. Guéraud ${ }^{6}$, J.P. Chapelle ${ }^{1 c}$, C. Kevers ${ }^{7}$, C. Charlier ${ }^{1 d}$, A. Albert ${ }^{1 \mathrm{e}}$ and J.O. Defraigne ${ }^{1 \mathrm{a}}$
}

${ }^{1} \mathrm{CHU}$ - University of Liège: ${ }^{1 a}$ Dept of Cardiovascular Surgery and CREDEC; ${ }^{16}$ Division of Diabetes, Nutrition and Metabolic Diseases; ${ }^{1 c}$ Service of Clinical Biology; ${ }^{1 d}$ Dept of Toxicology; ${ }^{1 e}$ Dept of Medical Informatic and Biostatistics; Sart Tilman, Liège, Belgium; ${ }^{2}$ University of Rennes I, Laboratory of Cellular and Vegetal Biology, Movement, Sport and Health Team, Rennes, France; ${ }^{3}$ LBFA/INSERM884 UFR of Pharmacy, La Tronche, Grenoble, France; ${ }^{4}$ University La Sapienza, Dept of Internal Medicine, Roma, Italy; ${ }^{5}$ Biofortis, Nantes, France; ${ }^{6}$ INRA UMR1089 Xenobiotics, Toulouse, France; ${ }^{7}$ University of Liège, Plant Molecular Biology and Biotechnology Unit, Sart Tilman, Liège, Belgium

\begin{abstract}
The present study was designed to test the hypothesis that an increased consumption of fruits and vegetables up to $600 \mathrm{~g}$ per day in type 2 diabetes patients can reduce oxidative damages to lipids. After a clinical examination, 29 type 2 diabetes patients were divided into two groups: the first one did not receive any special instructions about the diet while the second one received fruits and vegetables consumption advices thanks to a picture catalogue describing types of fruits and vegetables as well as quantities to be eaten every day. After two months of intervention, plasma concentrations in vitamin $C, \beta$-carotene and polyphenols remained unchanged in both groups when compared to baseline values. No significant decrease in lipid peroxidation as evidenced by nine biomarkers (malonaldehyde as TBAR's, lipid peroxides, oxidized LDL, antibodies against oxidized LDL, isoprostanes, 7-keto-cholesterol, 7 $\beta$ hydroxycholesterol, 4-hydroxynonenal metabolite, LDL size) was also noted. In conclusion, our findings confirmed the fact that the effect of high intake of fruits and vegetables on reducing oxidative damage to lipids remains largely controversial even in patients having an oxidative stress profile. Moreover, the present leaves open the question of the most appropriate markers of lipid peroxidation since only small correlations were evidenced between the large battery of tests investigated.
\end{abstract}

Keywords: Oxidative stress, lipid peroxidation, fruits, vegetables.

\section{INTRODUCTION}

Oxidative stress (OS) is defined as an imbalance between oxidants or reactive oxygen species (ROS) and antioxidants in favour of the oxidants, leading to a disruption of redox signalling and/or molecular damage [1]. More and more, OS is recognized as playing a key role in the development of cardiovascular diseases and degenerative pathologies such as cancer. If ROS have physiological properties, they become, however, toxic if produced in excess. Due to their high reactivity, ROS can easily interact with essential substrates such as lipids, proteins and DNA. The oxidative modification of lipids (lipid peroxidation) induced by ROS-mediated processes is actually well - recognized to be an important and presumably intermediate step in the formation of atherosclerosis plaques and lesions [2-5]. To limit the harmful effects of ROS, a high-performance antioxidant system consisting of enzymes, proteins, vitamins ( $A, C$ and $E)$, carotenoids, polyphenols, trace elements and small molecules, such as glutathione, interact with ROS in order to regulate their production down to the physiological range.

*Address corresponding to this author at the Dept of Cardiovascular Surgery and CREDEC, Belgium; Tel: 0032474837071; Fax: 003243667164;

E-mail: J.Pincemail@chu.ulg.ac.be
A large number of epidemiological studies indicate that a daily consumption of fruits and vegetables may contribute to significantly reduce the incidence of cardiovascular diseases [6-9]. Potential health effects of fruit and vegetables are mainly attributed to the content in specific ingredients having antioxidant properties such as vitamins $\mathrm{C}$ and $\mathrm{E}$, carotenoids and a wide range of bioactive compounds such as polyphenols $[10,11]$. Actually, public health recommendations arising from the World Health Organization (WHO) specify to consume at least 5 fruits and vegetables daily [12,13]. Behind this message, some questions need, however, to be clarified.

Firstly, there is some confusion in the literature about the '5-a-day' healthy eating message conveyed among our Western populations [14]. Some authors speak about 5 servings of fruits and vegetables per day while others mean 5 fruits and vegetables daily. Despite there is no definite consensus about the average portion size [15], the standard portion of fruits and vegetables is yet considered to be $80 \mathrm{~g}$. So eating 5 servings of fruit and vegetables would amount a total of $400 \mathrm{~g}$ of these foods each day. For that, it is 
important to know the weight of these foods. As an orange can weight $140 \mathrm{~g}$, eating one is the equivalent of 2 servings. Inversely, it should be necessary to eat 3 plums to have a serving since their weight is about 30 g. Thus, eating 5 fruit and vegetables per day does not allow to necessarily reach the recommended amount of $400 \mathrm{~g} / \mathrm{d}$.

Secondly, it is still unclear whether diets rich in fruit and vegetables are effectively capable in humans to reduce in vivo lipid peroxidation [16-24]. Indeed, most interventional studies with fruit and vegetables were conducted on presumably healthy people not particularly prone to enhanced lipid peroxidation processes. Another difficulty is that the quest for more appropriate biomarkers of in vivo lipid peroxidation is always a great challenge issue in clinical research. The measurement of malondialdehyde (MDA), as a by product of lipid peroxides, is the most popular assay used in studies. Unfortunately, the specificity of this useful biomarker has been largely questioned so that data interpretation has to be taken with great caution.

The goal of the present study was to test the hypothesis that an increased consumption of fruits and vegetables up to $600 \mathrm{~g}$ per day could be able to reduce oxidative damages to lipids in a pathology associated with increased OS. We have selected type 2 diabetes, a metabolic disease that leads to high blood sugar due to either insulin deficiency, insulin resistance or both. Chronic inflammation and, overall, glucose auto oxidation are the main sources that contribute to increase ROS production in this pathology [25]. Of interest is that type 2 diabetes leads to a high incidence of macro - vascular complications (atherosclerosis, cardiovascular diseases), which are clearly linked to oxidative damages to lipids [26]. With respect to that, we used nine different biomarkers in order to evidence how a regular intake of fruit and vegetables may modulate the lipid peroxidation phenomenon in patients suffering type 2 diabetes.

\section{MATERIAL AND METHODS}

\section{Patients}

A group of 29 type 2 diabetic patients was recruited on a voluntary basis among those attending the outpatient clinic of the Department of diabetes and metabolic diseases, University Hospital of Liège. Patients were asked to arrive between 8 and 10 a.m. for a $35 \mathrm{~mL}$ blood sample collection. Subjects were fasted for at least $12 \mathrm{~h}$ and not allowed to drink fruit juice or to perform physical activity the day before the visit. Blood samples were drawn on EDTA anticoagulant or clot activating gel depending on the parameter. Blood samples were immediately centrifuged on site and plasma or sera were frozen on dry ice. In addition, a urine sample of $10 \mathrm{~mL}$ was also collected. Patient characteristics were recorded including age, height, weight, blood pressure, smoking habits, alcohol and drugs consumption and physical activity. The body mass index (BMI) was calculated from height and weight $\left(\mathrm{kg} / \mathrm{m}^{2}\right)$. The study protocol was approved by the University Hospital Ethics Committee for medical research investigations. All participants received a written document describing the goal of the study and signed an informed consent form prior to enrolment. They also completed a home-made food questionnaire for evaluating their intake of fruit and vegetables.

The 29 study patients (baseline mean age: $50 \pm 15$ years; plasma glucose and glycosylated haemoglobin $\left(\mathrm{HbA}_{1 \mathrm{C}}\right)$ levels respectively equal to $1.77 \pm 0.62 \mathrm{~g} / \mathrm{L}$ and $8.64 \pm 1.28 \%$ ), with a median fruits and vegetables consumption of $\pm 300 \mathrm{~g} / \mathrm{d}$, were randomly divided into two groups. The first group $(n=15)$ did not receive any special instructions about the diet but was asked to compel in a diary the daily consumption in fruits and vegetables (control group). The second group of patients $(n=14)$ received fruits and vegetables consumption advices and had to follow a strict intervention diet (diet group). The latter consisted of a well-defined 2-month menu with recipes designed to reach an intake of $600 \mathrm{~g}$ of fruits and vegetables each day. A picture catalogue describing types of fruits and vegetables as well as quantities to be eaten everyday was developed to help participants respecting the imposed diet (see Figure $\mathbf{1}$ as an example). At the end of the 2-month study duration, patients of both groups (control and diet) were appointed for a second visit at which the dietary and biochemical parameters were reassessed.

\section{Antioxidant Determination}

For vitamin $\mathrm{C}$ determination, $0.5 \mathrm{~mL}$ plasma was immediately transferred to ice-cold tubes containing 0.5 $\mathrm{mL}$ of $10 \%$ metaphosphoric acid. The whole mixture was frozen on ice packs. Analyses were performed on the day of blood collection by a spectrophotometric method using the reduction of 2,6-dichlorophenolindophenol (Perkin Elmer Lambda 40 Norwalk, USA) [27]. Plasma vitamin $E$ ( $\alpha$ and $\gamma$-tocopherols) and $\beta$ carotene were determined simultaneously by HPLC procedure (Alliance Waters, USA) coupled with a diode 
Breakfast : 1 orange $(+/-100 \mathrm{~g})$

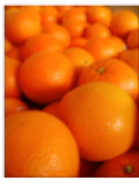

Collation 10h : 1 apple $(+/-130 \mathrm{~g})$

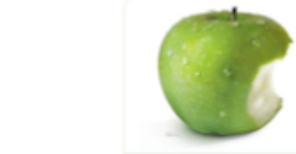

Dinner : $+/-150 \mathrm{~g}$ de green beans

(+/- 6 soap spoons)

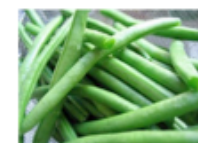

Souper : $100 \mathrm{~g}$ tomatos and $100 \mathrm{~g}$ lettuce

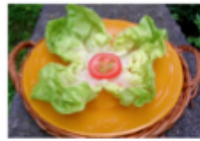

Collation 20h : 1 kiwi $(+/-80 \mathrm{~g})$

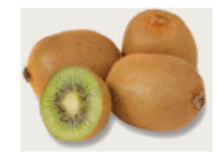

Figure 1: Illustration of a page issued from the picture catalogue describing types of fruits and vegetables as well as quantities $(+/-$ total of $600 \mathrm{~g})$ to be eaten everyday.

array detector (PDA 2996, Waters, USA) [28]. For total polyphenol determination, $1.5 \mathrm{~mL}$ of EDTA-plasma was added $1 \mathrm{~mL}$ dichloromethane and $400 \mu \mathrm{L} \mathrm{H}_{2} \mathrm{O}$. After 3 min homogenisation, the mixture was centrifuged $\left(4000 \mathrm{~g}, 10 \mathrm{~min}, 4^{\circ} \mathrm{C}\right)$. The aqueous phase was kept and the dichloromethane phase was again extracted with $500 \mu \mathrm{L} \mathrm{H}_{2} \mathrm{O}$. The two aqueous phases were mixted and total polyphenol measurement was done on the mixture by Folin Ciocalteu reagent [29].

\section{Oxidative Damage to Lipids}

\section{Thiobarbituric Acid Reactives Substances (TBAR's)}

Plasma TBAR's were determined using the fluorimetric determination of malondialdehyde (MDA)TBA (thiobarbituric acid) complex after extraction with n-butane $[30,31]$

\section{Lipid Peroxides}

The analysis of lipid peroxides $(\mathrm{ROOH})$ as markers of the oxidative damage to lipids was performed with the commercial kit (Oxystat, Biomedica Gruppe, Austria). Briefly, the peroxide $(-\mathrm{OOH})$ concentration was determined spectrophotometrically by reaction of the biological peroxides with peroxidase and a subsequent colour reaction using 3,3',5,5'tetramethylbenzidine as substrate.

\section{Oxidized LDL and Autoantibodies}

Oxidized low-density lipoprotein (LDL) in plasma samples was determined spectrophotometrically with a competitive enzyme-linked immunosorbent assay (ELISA) kit (Immunodiagnostik, Germany). The titre in free antibodies (IgG) against oxidized LDL (Ab-OxLDL) was assessed with a commercial enzyme immunoassay (Biomedica Gruppe, Austria) using $\mathrm{Cu}^{2+}$ oxidized LDL as antigen.

\section{4-Hydroxynonenal Metabolite}

1,4-dihydroxynonane mercapturic acid (DHN-MA), the major urinary metabolite of 4-hydroxynonenal (end product of lipid peroxide) in urine, was achieved using competitive enzyme immunoassay as previously described, using DHN-MA-linked acetylcholinesterase enzyme as tracer [32].

\section{High Sensitive and Specific Oxidative Stress Biomarkers}

Two isotope-dilution mass spectrometry methods to measure lipid peroxidation, including arachidonate and cholesterol, were used. As arachidonic acid oxidation, we measured the isoprostane iPF2 $\alpha$-III. Plasma was treated with alkaline hydrolysis and loaded to immunoaffinity column before LC/MS analysis according to Sircar et al. [33] with minor modification [34]. For cholesterol oxidation markers, 2 oxysterols, 7 ketocholesterol and 7 $\beta$-hydroxycholesterol were measured by mass GS/MS as previously reported $[35,36]$. 


\section{Miscellaneous}

The Lipoprint system -low density lipoprotein (LDL) subfractions kit (Quantimetrix, $n^{\circ}$ 48-7002) allows separating as a function of size the seven sub-fractions of LDL present in serum and plasma. The Lipoprint system utilizes non-denaturing, linear (non-gradient) polyacrylamide gel electrophoresis (PAGE) to separate and measure lipoprotein fractions and subfractions (large buoyant LDL 1-2; small dense LDL 3 through 7). The test uses a lipophilic dye that binds to cholesterol in the lipoprotein particle prior to electrophoresis. The electrophoresed gels were scanned with Lipoware software to determine the relative area of each lipoprotein subfraction which was multiplied by total cholesterol of the sample (determined with Hitachi 911 and assay kit Roche Diagnostics ref 11489232) to calculate the amount of cholesterol of each subfraction. A quality control specimen (Liposure-ref 48-7060 Quantimetrix) validates electrophoresis LDL size.

Serum PON1 activity towards paraoxon was analysed by spectrophotometry as described previously [37]. Briefly $15 \mu \mathrm{L}$ of serum sample was added to 250

Table 1: Basal Demographic and Biochemical Data in Diabetes Patients Without Specific Advices and in Diabetes Patients Receiving Advices Leaflet for Increasing Fruits and Vegetables Intake

\begin{tabular}{|c|c|c|c|}
\hline & $\begin{array}{l}\text { Control group } \\
\qquad(\mathrm{N}=15)\end{array}$ & $\begin{array}{l}\text { Diet group } \\
(\mathrm{N}=14)\end{array}$ & P-value \\
\hline gender & 8 women and 7 men & 5 women and 9 men & \\
\hline age (years) & $57.0 \pm 6.7$ & $60 \pm 4.2$ & 0.78 \\
\hline smoking habits & 2 & 5 & \\
\hline $\mathrm{BMI}\left(\mathrm{kg} / \mathrm{m}^{2}\right)$ & $30.1 \pm 2.3$ & $30.6 \pm 3.6$ & 0.56 \\
\hline \multicolumn{4}{|l|}{ biochemical parameters } \\
\hline \multicolumn{4}{|l|}{ a. glycemia } \\
\hline glucose (g/L) & $1.73 \pm 0.57$ & $1.83 \pm 0.69$ & 0.66 \\
\hline glycosylated $\mathrm{Hb}(\%)$ & $8.83 \pm 1.42$ & $8.26 \pm 1.14$ & 0.45 \\
\hline insuline (mU/L) & $13.9 \pm 13.1$ & $17.8 \pm 15.9$ & 0.48 \\
\hline \multicolumn{4}{|l|}{ b. antioxidants } \\
\hline total polyphenols $(\mathrm{mg} / \mathrm{mL})$ & $2.60 \pm 0.48$ & $2.78 \pm 0.44$ & 0.33 \\
\hline vitamin $\mathrm{C}(\mu \mathrm{g} / \mathrm{mL})$ & $8.54 \pm 2.82$ & $10.25 \pm 3.62$ & 0.20 \\
\hline$\beta$-carotene (mg/L) & $0.17 \pm 0.14$ & $0.12 \pm 0.10$ & 0.39 \\
\hline$\alpha$-tocopherol $(\mu \mathrm{g} / \mathrm{mL})$ & $12.02 \pm 2.75$ & $14.28 \pm 4.03$ & 0.091 \\
\hline$\gamma$-tocopherol $(\mu \mathrm{g} / \mathrm{mL})$ & $0.93 \pm 0.50$ & $0.95 \pm 0.38$ & 0.03 \\
\hline \multicolumn{4}{|l|}{ c. markers of lipid peroxidation } \\
\hline lipid peroxides $(\mu \mathrm{M})$ & $391 \pm 176$ & $460 \pm 221$ & 0.36 \\
\hline oxidized LDL (ng/mL) & $350 \pm 338$ & $567 \pm 514$ & 0.095 \\
\hline Ab-Ox-LDL (UI/L) & $271 \pm 3.2$ & $270 \pm 3.9$ & 0.58 \\
\hline LDL size $(\AA ̊)$ & $390 \pm 342$ & $363 \pm 269$ & 0.82 \\
\hline TBARs $(\mu \mathrm{M})$ & $3.37 \pm 0.43$ & $3.47 \pm 0.40$ & 0.53 \\
\hline DHN-MA (ng/mL) & $4.66 \pm 4.60$ & $3.82 \pm 1.89$ & 0.55 \\
\hline 7 keto-cholesterol (ng/mL) & $14.5 \pm 4.69$ & $19.1 \pm 15.3$ & 0.28 \\
\hline $7 \beta$-hydroxycholesterol (ng/mL) & $17.6 \pm 7.46$ & $18.9 \pm 11.2$ & 0.71 \\
\hline isoprostanes $(\mathrm{pg} / \mathrm{mL})$ & $22.3 \pm 5.74$ & $24.0 \pm 3.23$ & 0.34 \\
\hline \multicolumn{4}{|l|}{ d. miscellaneous } \\
\hline cholesterol (g/L) & $1.50 \pm 0.49$ & $1.67 \pm 0.42$ & 0.34 \\
\hline paraoxonase $(\mu \mathrm{M})$ & $111 \pm 72$ & $115 \pm 84$ & 0.89 \\
\hline sVCAM (ng/mL) & $814 \pm 201$ & $749 \pm 218$ & 0.42 \\
\hline iVCAM (ng/mL) & $298 \pm 95$ & $287 \pm 96$ & 0.77 \\
\hline
\end{tabular}


$\mu \mathrm{L}$ of substrate solution $(100 \mathrm{mmol} / \mathrm{L}$ Tris- $\mathrm{HCl}, 2$ $\mathrm{mmol} / \mathrm{L} \mathrm{CaCl}, 5.5 \mathrm{mmol} / \mathrm{L}$ paraoxon, $\mathrm{pH}$ 8.0). After 2 and 5 minutes, absorbance readings at $415 \mathrm{~nm}$ were taken. SICAM and SVCAM were detected in serum by using commercial kits developed by commercial kits (R\&D systems, Abingdon, United Kingdom). Glucose (Roche), glycosylated haemoglobin (Menarini) and insulin (Roche) were detected according to classical routine techniques with the use of commercial kits.

\section{Statistics}

Results were expressed as mean \pm standard deviation (SD) for quantitative variables, while frequencies and proportions (\%) were used for categorical variables. Mean values between the two study groups were compared by Student's t test while proportions were compared by the chi-squared test for contingency tables. Non parametric tests were used for skewed distributions. The change in parameters between the two visits within individuals was tested by the paired Student t-test or the Wilcoxon signed rank test for continuous variables. Correlation coefficients were calculated for measuring the association between two biomarkers. Calculations were always carried out on the maximum number of data available. Missing data were not replaced. Results were considered to be significant at the $5 \%$ critical level $(p<0.05)$ Data analysis was carried out using SAS (version 9.1 for Windows) and S-PLUS (version 6.2) statistical packages.

\section{RESULTS}

As seen in Table 1, the demographic and biochemical characteristics were comparable in the two groups (control and diet) at baseline. As expected, mean plasma values reflecting the glycaemic status (glucose, glycosylated haemoglobin, insulin) of the patients were above the laboratory reference values. Plasma antioxidants (vitamins $\mathrm{C}$ and $\mathrm{E}, \beta$-carotene and polyphenols) concentrations were also similar in the two groups For the oxidative parameters (lipid peroxides, oxidized LDL, antibodies against oxidized LDL, TBAR'S, DHN-MA, 7-ketocholesterol and 7 $\beta$ hydroxycholesterol, isoprostanes, LDL size), no significant difference was evidenced either. The two randomized groups showed also the same concentrations in paraoxonase, SVCAM and iVCAM. Finally results from the home-made questionnaire revealed that the intake of fruits and vegetables before the study were $300 \mathrm{~g} / \mathrm{d}$ in both groups.

Table 2 displays for all the patients the baseline correlations between all biomarkers generally used for the assessment of the in vivo lipid peroxidation processes. Antibodies against oxidized LDL showed a significant negative correlation with lipid peroxides $(r=$ -0.52; $p=0.0035)$, isoprostanes $(r=-0.38 ; p=0.046)$ and TBAR's $(r=-0.32 ; p=0.09)$. The parameter 17 keto-cholesterol was positively correlated with $17 \beta$ hydroxycholesterol $(r=0.43 ; p=0.019)$, lipid peroxides $(r=0.36 ; p=0.05)$ and oxidized LDL $(r=0.37 ; p=$ $0.05)$. Finally, LDL size was negatively correlated with oxidized LDL $(r=-0.36 ; p=0.05)$.

Figure 2 shows that intake of fruits and vegetables significantly increased from $300 \pm 85 \mathrm{~g} / \mathrm{d}$ to $629 \pm 17$ $\mathrm{g} / \mathrm{d}(\mathrm{p}=0.04)$ in the diet group while a slight but significant increase $(300 \pm 85 \mathrm{~g} / \mathrm{d}$ to $408 \pm 36 \mathrm{~g} / \mathrm{d}, \mathrm{p}=$ $0.05)$ was also observed in the control group. Despite such observation, no significant difference was seen in the plasma concentrations of antioxidants (vitamin C, $\beta$-carotene, polyphenols) in control and, surprisingly, in

Table 2: Correlation between Biomarkers of Lipid Peroxidation Measured on 29 Type 2 Diabetes Patients at the Start of the Study. Statistical Significance is Discussed in the Text

\begin{tabular}{|c|c|c|c|c|c|c|c|c|c|}
\hline & $\begin{array}{l}\text { lipid } \\
\text { peroxides }\end{array}$ & $\begin{array}{l}\text { oxidized } \\
\text { LDL }\end{array}$ & $\begin{array}{l}\text { Ab-Ox- } \\
\text { LDL }\end{array}$ & TBAR's & $\begin{array}{c}\text { DHN- } \\
\text { MA }\end{array}$ & $\begin{array}{l}7 \text { keto- } \\
\text { cholesterol }\end{array}$ & $\begin{array}{c}7 \beta- \\
\text { hydroxycholesterol }\end{array}$ & isoprostane & $\begin{array}{l}\text { LDL } \\
\text { size }\end{array}$ \\
\hline lipid peroxides & 1 & -0.04 & -0.52 & -0.01 & -0.24 & 0.36 & 0 & 0.23 & 0.37 \\
\hline oxidized LDL & -0.04 & 1 & 0.23 & -0.17 & -0.15 & 0.37 & 0.09 & 0.1 & 0.02 \\
\hline Ab-Ox-LDL & -0.52 & 0.23 & 1 & -0.32 & 0.18 & -0.17 & -0.24 & -0.38 & -0.02 \\
\hline TBAR's & -0.01 & -0.17 & -0.32 & 1 & -0.22 & -0.03 & -0.03 & 0.22 & -0.31 \\
\hline DHN-MA & -0.24 & -0.15 & 0.18 & -0.22 & 1 & -0.05 & -0.11 & -0.05 & 0.11 \\
\hline 7 keto-cholesterol & 0.36 & 0.37 & -0.17 & -0.03 & -0.05 & 1 & 0.43 & -0.12 & -0.11 \\
\hline $7 \beta$-hydroxycholesterol & 0 & 0.09 & -0.24 & -0.03 & -0.11 & 0.43 & 1 & -0.04 & -0.36 \\
\hline isoprostane & 0.23 & 0.1 & -0.38 & 0.22 & -0.05 & -0.12 & -0.04 & 1 & 0.04 \\
\hline LDL size & 0.37 & 0.02 & -0.02 & -0.31 & 0.11 & -0.11 & -0.36 & 0.04 & 1 \\
\hline
\end{tabular}






Figure 2: Intake of fruits and vegetables before and after diet intervention in diabetes patients receiving no special diet advices (white columns) and diabetes patients receiving a fully defined 2 months menu of recipes in order to reach an intake of $600 \mathrm{~g}$ of fruit and vegetables each day (black columns). ${ }^{*} p<0.05$.

Table 3: Evolution of Glycaemia Index, Antioxidants and Markers of Lipid Peroxidation Before and After a Diet Enriched or Not in Fruits and Vegetables in Type 2 Diabetes Patients

\begin{tabular}{|c|c|c|c|c|c|c|}
\hline \multirow[b]{2}{*}{ parameter } & \multicolumn{2}{|c|}{ Control group } & \multirow[b]{2}{*}{ P-value } & \multicolumn{2}{|c|}{ Diet group } & \multirow[b]{2}{*}{ P-value } \\
\hline & Baseline & 2-month visit & & Baseline & 2-month visit & \\
\hline \multicolumn{7}{|l|}{ glycemia index } \\
\hline glycosylated $\mathrm{Hb}(\%)$ & $8.83 \pm 1.42$ & $7.93 \pm 0.81$ & 0.069 & $8.46 \pm 1.14$ & $8.26 \pm 0.65$ & 0.47 \\
\hline insuline (mU/L) & $13.9 \pm 13.1$ & $11.2 \pm 11.2$ & 0.28 & $17.8 \pm 15.9$ & $18.4 \pm 25.0$ & 0.86 \\
\hline $\begin{array}{l}\text { total polyphenols } \\
(\mathrm{mg} / \mathrm{mL})\end{array}$ & $2.60 \pm 0.48$ & \pm 0.38 & 0.35 & $2.78 \pm 0.44$ & $2.84 \pm 0.46$ & 0.68 \\
\hline vitamin $\mathrm{C}(\mu \mathrm{g} / \mathrm{mL})$ & $8.5 \pm 2.83$ & $9.2 \pm 2.94$ & 0.45 & $10.3 \pm 3.62$ & $10.4 \pm 2.99$ & 0.44 \\
\hline$\beta$-carotene (mg/L) & $0.17 \pm 0.14$ & $0.16 \pm 0.13$ & 0.82 & $0.12 \pm 0.10$ & $0.11 \pm 0.08$ & 0.54 \\
\hline$\alpha$-tocopherol $(\mu \mathrm{g} / \mathrm{mL})$ & $12.0 \pm 2.75$ & $13.3 \pm 3.68$ & 0.07 & $14.3 \pm 4.03$ & $13.2 \pm 2.77$ & 0.22 \\
\hline oxidized LDL (ng/mL) & $350 \pm 338$ & $440 \pm 452$ & 0.26 & $567 \pm 514$ & $427 \pm 185$ & 0.2 \\
\hline Ab-Ox-LDL (UI/L) & $390 \pm 342$ & $408 \pm 406$ & 0.81 & $363 \pm 269$ & $428 \pm 351$ & 0.44 \\
\hline LDL size $(\AA)$ & $271 \pm 3.2$ & $271 \pm 3.2$ & 0.65 & $270 \pm 3.9$ & $272 \pm 2.4$ & 0.27 \\
\hline TBARs $(\mu \mathrm{M})$ & $3.37 \pm 0.43$ & $3.32 \pm 0.33$ & 0.65 & $3.47 \pm 0.44$ & $3.31 \pm 0.44$ & 0.14 \\
\hline DHN-MA (ng/mL) & $4.66 \pm 4.60$ & $5.3 \pm 6.3$ & 0.64 & $3.82 \pm 1.89$ & $5.12 \pm 3.86$ & 0.1 \\
\hline $\begin{array}{c}7 \text { keto-cholesterol } \\
(\mathrm{ng} / \mathrm{mL})\end{array}$ & $14.5 \pm 4.69$ & $17.0 \pm 10.1$ & 0.34 & $19.1 \pm 15.5$ & $16.0 \pm 13.0$ & 0.62 \\
\hline $\begin{array}{c}7 \beta \text {-hydroxycholesterol } \\
(\mathrm{ng} / \mathrm{mL})\end{array}$ & $17.6 \pm 7.46$ & $20.0 \pm 13.2$ & 0.43 & $19.0 \pm 11.2$ & $18.7 \pm 15.6$ & 0.97 \\
\hline isoprostanes $(\mathrm{pg} / \mathrm{mL})$ & $22.3 \pm 5.74$ & $21.5 \pm 6.97$ & 0.56 & $24 \pm 3.23$ & $22.3 \pm 5.03$ & 0.13 \\
\hline
\end{tabular}


the diet groups (Table 3). As far as the markers of lipid peroxidation are concerned, the concentration of lipid peroxides and ox-LDL tended to increase in the control group while a decrease in lipid peroxides, ox-LDL and 7 - ketocholesterol was noted in the diet group.

\section{DISCUSSION}

Diabetes is associated with a higher risk of developing cardiovascular diseases. Since an increase of the oxidative stress is present in type 2 diabetic patients [38], it may sound that an optimization of the antioxidant defences could lead to a reduction of the cardiovascular risk factors linked to oxidative stress in such patients. Until now, studies on cardiovascular prevention were essentially conducted by using food complements containing antioxidants and trace elements. From a general point of view, results were rather disappointing because of a lack of uniformity in the recommended doses and the used associations of antioxidants. Recently, the interest for antioxidants has been shifted from surrogate supplements to the primary natural sources of whole fruits and vegetables. A large number of epidemiological but also interventional studies have highlighted the relevant preventive aspects of this natural antioxidant supply on diabetes prevention $[39,40]$.

To quantify the preventive support from a cardiovascular point of view, analytical tools should be available to measure and monitor the oxidative stress status. In type 2 diabetic patients, as a consequence of hyperglycaemia, there is an increased formation of ROS responsible of oxidative damage to lipids, proteins and DNA. This results in an accumulation of oxidized LDL components into the arterial wall where they contribute, in presence of macrophages, to the formation of the atheroma plaque. Due to methodological reasons, it remains difficult to estimate the presence of in vivo lipid peroxidation. In the majority of studies, malondialdehyde (MDA) detected by the thiobarbituric acid or by HPLC is the most popular assay despite its lack of specificity. Recently, the measurement of isoprostanes, whose formation arises from direct reaction of arachidonic acid with ROS, emerged as a gold standard for evidencing lipid oxidation. This highly specific assay is nonetheless time consuming and expensive. The detection of lipid peroxides, ox-LDL and antibodies against ox-LDL can now be achieved routinely in the clinical biology. Recently, we published normal reference values for lipid peroxides $(0-432 \mu \mathrm{M})$, oxidized LDL (0-500 UI/L) and Ab-Ox-LDL (200-600 UI/L) [41,42]. Referring to
Table 1, it was evidenced that a large number of type 2 diabetic patients presented values beyond the upper reference value for these markers. In the present study, we also decided to investigate the measurement of specific oxidative damage to cholesterol with the measurement of 7 - ketocholesterol and $7 \beta$ hydroxycholesterol. This test panel was completed by the evaluation of LDL size. Low density lipoprotein (LDL) particles display a heterogeneity in size and density which has been well documented This heterogeneity has clinical relevance, in that small, dense LDL particles which are more sensitive to oxidative damage than large, buoyant LDL, are suspected to be associated with an increased risk of coronary artery disease [43]. Finally, we used a new biomarker, namely the 1,4-dihydroxynonane mercapturic acid (DHN-MA), recognised to be the major urinary metabolite of 4-hydroxynonenal, another end product of lipid peroxides [32]. As shown on Table 2, there were only few and weak correlations between all these parameters although they are all supposed to evidence lipid peroxidation processes. This highlights all the difficulty to choose the appropriate biomarker. In the multicentre study «Biomarkers of Oxidative Stress Study (BOSS) ", using administration of different concentrations of CCL4 in rats as acute model_of oxidative stress [44], it has been shown that the most sensitive marker for lipid peroxidation evidence was 15F2t-IsoP in plasma and urine. In contrast, MDA in urine was a moderately sensitive marker whereas hydroperoxides and TBAR's in urine were not sensitive at all. Here, among all parameters, only 7 ketocholesterol was positively correlated with other biomarkers of lipid peroxidation, specifically lipid peroxides $(r=0.36 ; p=0.05)$ and oxidized LDL $(r=$ $0.37 ; p=0.05)$.

At baseline, all diabetic patients had an average intake of $300 \mathrm{~g} / \mathrm{d}$ of fruits and vegetables. This intake was in agreement with the national observations made in Belgium [45] but largely below the amount of 400$600 \mathrm{~g}$ recommended by WHO [46]. Our study demonstrates that it is possible to increase the intake of fruits of vegetables up to $629 \pm 17 \mathrm{~g} / \mathrm{d}$ when specific advice illustrated by a detailed pictures catalogue can be provided. Surprisingly, a slight increase from $302 \pm$ $85 \mathrm{~g} / \mathrm{d}$ to $408 \pm 36 \mathrm{~g} / \mathrm{d}$ was also noted in the control group. The fact that the local ethics committee imposed to inform all participants about the study's primary objective, has perhaps motivated the participants of the control group to give more attention to their intake of fruits and vegetables. Nevertheless, the increase was largely below those observed with the diet group. 
As fruits and vegetables are recognized for their high content in antioxidants, this should have been reflected in the diet group in an increased load of antioxidants in the bowel and absorption with a resulting rise in the circulation. However, no such change was observed in the plasma concentrations of the antioxidants. For vitamin $\mathrm{C}$, it has been reported that a significant rise in plasma concentration can only be detected after an increase in fruits and vegetables consumption when the subject presents a low basal vitamin $C$ concentration $(<6 \mu \mathrm{g} / \mathrm{mL})$ [24]. This is not the case in our study since basal rates in vitamin $C$ were for all patients comprised in the well accepted normal range $[41,42]$. Another explanation for the lack of increase could be due to the time of intervention. Indeed, Polidori et al. [23] have shown that the plasma concentration in vitamin $\mathrm{C}$ only significantly increased after 3 - months and not 2 - months intervention with daily portions of fruits and vegetables. Considering $\beta$ carotene, previous studies have demonstrated an elevation of plasma concentration after increased fruits and vegetables consumption only when basal plasma rates were comprised between 0.2 and $0.3 \mathrm{mg} / \mathrm{L}$. As our patients exhibited at baseline a slightly lower but quite similar $\beta$-carotene concentration $(0.11 \mathrm{mg} / \mathrm{L})$, we have no logical argument to explain why levels remained unchanged. It is known however that $\beta$ carotene bioavailability is higher when food is cooked with fat and lower raw food is consumed [47]. Furthermore it is also possible that $\beta$-carotene was not the best marker for the increase of carotenoids in our study patients because several reports failed to find a positive association between intake of lycopene, another carotenoid, and serum concentration [48].

The present study has also evidenced that increasing the consumption of fruits and vegetables from $300 \mathrm{~g} / \mathrm{d}$ to $600 \mathrm{~g} / \mathrm{d}$ did not result in a significant decrease of the patient's glycaemic status. With respect to oxidative damage to lipids, no significant effect of increased fruits and vegetables intake was also observed regardless of the biomarker used. Several tendencies may be worth mentioning: an increase of lipid peroxides (7\%), 7 keto-cholesterol (16 $\%)$ and oxidized LDL (25.7\%) in the control group and a decrease of the same markers, respectively, 15.5, 16.6 and $25 \%$, in the diet group.

Globally, our findings are in agreement with those of previous studies indicating that a decrease in the biomarkers of oxidative stress did not occur after increased fruits and vegetables intake [16-24,49,50] despite or not an improvement of the plasma antioxidant status. One explanation for this absence of effect could be due to the fact that all these studies enrolled presumably healthy subjects at low risk of presenting oxidative damage to lipids. Recently, Gimmarioli et al. [51] showed that a $700-1000 \mathrm{~g} / \mathrm{d}$ intake of fruits and vegetables in type 2 diabetic patients was associated with a decrease of MDA when compared to control patients receiving no dietary advice. Here we were unable to confirm this observation. Actually, TBAR's concentration is known to be positively related to glycaemia [52]. It has also been related that cinnamon, a natural polyphenol present in fruits acting as insulino - sensibilizer, was able to decrease glycemia in correlation to TBAR's concentration [53]. As we were unable to prove any modification on the glycaemic level with or without diet advice, this partially the absence of modification in TBAR's concentrations.

\section{CONCLUSION}

This study shows that diet advice based on an illustrated catalogue can help increase the intake of fruits and vegetables up to $600 \mathrm{~g} / \mathrm{d}$ in type 2 diabetes patients known to be in a situation of oxidative stress. Despite such an increase, no significant change in blood levels of antioxidant parameters and glycaemic markers could be evidenced. In our study patients, both vitamin $C$ and $\beta$-carotene levels at baseline were within reference ranges. This may explain the lack of incidence of increased intake of fruits and vegetables on the plasma levels in these antioxidants. Compared to data published in the literature, our findings confirmed the fact that the effect of high intake of fruits and vegetables on reducing oxidative damage to lipids remains largely controversial. When compared to control patients, subjects in the diet group just showed a tendency to decrease three of the biomarkers of the oxidative stress, namely oxidized LDL, 7 ketocholesterol and lipid peroxides. Lastly, the present leaves open the question of the most appropriate markers of lipid peroxidation since only small correlations were evidenced between tests of the large battery of tests investigated here above.

\section{ACKNOWLEDGEMENTS}

The authors thank Jean-Paul Cheramy-Bien for his precious technical assistance.

\section{FUNDING SOURCES}

This project was fully supported by FIRS grant 4706 of the University hospital of Liège. 


\section{AUTHORS' CONTRIBUTION}

The present study was conducted at the University Hospital of Liège, Belgium. Professor JO Defraigne and Dr. Sc J Pincemail (CREDEC and Dept of Cardiovascular Surgery) were the main coordinators of the study. They collected all data and wrote the manuscript in the present form. Patients were recruited the Dept of Diabetology (University Hospital of Liège) managed by Professor N Paquot. Professor C Charlier and Professor JP Chapelle (University Hospital of Liège, Laboratories of Clinical Biology) allowed the analysis of vitamin $E, \beta$-carotene, lipid peroxides, oxidized LDL and antibodies against oxidized LDL while vitamin $\mathrm{C}$ determination was performed by Mr JP Cheramy-Bien (CREDEC). Dr Sc C Kevers developed the methodology for the analysis of blood polyphenols. Professor J Cillard from Rennes University (France), Professor L luliano from La Sapienza University (Italy), Professor I Hininger from Grenoble University (France), Professor F Gueraud from Toulouse University (France) were respectively involved in the detection of isoprostanes, hydroxycholesterol, TBAR's and 4hydroxynonenal metabolite. Dr Cazaubiel from Biofortis (France) determined the LDL size. Professor A Albert (Dpt of Medical Informatics and Biostatistics of Liège University) was involved in the statistical analysis of all data. All investigators critically revised the manuscript for the intellectual content and gave their final approval of the version to be published.

\section{REFERENCES}

[1] Jones DP. Redefining oxidative stress. Antioxid Redox Signal 2006; 8: 1865-79. http://dx.doi.org/10.1089/ars.2006.8.1865

[2] Inoue T, Uchida T, Kamishirado H, Takayanagi K, Morooka S. Antibody against oxidized low density lipoprotein may predict progression or regression of atherosclerotic coronary artery disease. J Am Coll Cardiol 2001; 37: 1871-76. http://dx.doi.org/10.1016/S0735-1097(01)01228-1

[3] Gross M, Steffes M, Jacobs D, Jacobs DR Jr, Yu X, Lewis L, Lewis CE, Loria CM. I.- Plasma F2-isoprostanes and coronary artery calcification: The CARDIA Study. Clin Chem 2005; 51: 125-31.

http://dx.doi.org/10.1373/clinchem.2004.037630

[4] Hozawa A, Jacobs D, Steffes M, Gross MD, Steffen LM, Lee $\mathrm{DH}$. Relationships of circulating carotenoid concentrations with several markers of inflammation, oxidative stress, and endothelial dysfunction: the Coronary Artery Risk Developpement in Young Adults (CARDIA)/ Young Adult Longitudinal Trends in Antioxidants (YALTA) Study. Clin Chem 2007; 53: 1-9.

http://dx.doi.org/10.1373/clinchem.2006.074930

[5] Sigala F, Kotsinas A, Savari P, Filis K, Markantonis S, lliodromitis EK, et al. Oxidized LDL in human carotid plaques is related to symptomatic carotid disease and lesion instability. J Vasc Surg 2010; 52: 704-13.

http://dx.doi.org/10.1016/j.jvs.2010.03.047
[6]

Uno K, Nicholls SJ. Biomarkers of inflammation and oxidative stress in atherosclerosis. Biomark Med 2010; 4: 361-73. http://dx.doi.org/10.2217/bmm.10.57

[7] Hung HC, Joshipura KJ, Jiang R, Hu FB, Hunter D, SmithWarner SA, et al. Fruit and vegetable intake and risk of major chronic disease. J Natl Cancer Inst 2004; 96: 1577-84. http://dx.doi.org/10.1093/jnci/djh296

[8] Liu S, Manson JE, Lee IM, Cole SR, Hennekens $\mathrm{CH}$, Willett WC, Buring JE. Fruit and vegetable intake and the risk of cardiovascular disease: the Women's Health Study. Am J Clin Nutr 2000; 72: 922-28.

[9] Ness AR, Powles JW. Fruit and vegetables, and cardiovascular disease: a review. Int J Epidemiol 1995; 26: $1-13$

http://dx.doi.org/10.1093/ije/26.1.1

[10] Yusuf S, Hawkan S, Ounpuu S, Dans T, Avezum A, Lanas F, et al. Interheart Study Investigators. Effect of potentially modifiable risk factors associated with myocardial infarction in 52 countries (the INTERHEART study): case-control study. Lancet 2004; 364: 937-52.

http://dx.doi.org/10.1016/S0140-6736(04)17018-9

[11] Lindsay DG, Astley SB. European research on the functional effects of dieary antioxidants - EUROFEDA. Mol Aspects Med 2002; 23: 1-38.

http://dx.doi.org/10.1016/S0098-2997(02)00005-5

[12] Morton LW, Abu-Amsha CR, Puddey IB, Croft KG. Chemistry and biological effects of dietary phenolic compounds: relevance to cardiovascular disease. Clin Exp Pharmacol Physiol 2000; 27: 152-59. http://dx.doi.org/10.1046/i.1440-1681.2000.03214.x

Cox DN, Anderson AS, Reynolds J, McKellar S, Lean ME, Mela DJ. Take five, a nutrition education program intervention to increase fruit and vegetable intakes: impact on consumer choice and nutrient intakes. Br J Nutr 1998; 80: 123-31.

\section{http://dx.doi.org/10.1017/S0007114598001020}

[14] http: //www.5aday.com

[15] Ashfield-Watt PA. Fruits and vegetables, 5+ a day: are we getting the message across? Asia Pac J Clin Nutr 2006; 15 245-52.

[16] Miller ER, Appel LJ, Risby TH. Effect of dietary patterns on measures of lipid peroxidation results from a randomised clinical trial. Circulation 1998; 98: 2390-5. http://dx.doi.org/10.1161/01.CIR.98.22.2390

[17] Freese R, Alfthan G, Jaujiainen M, Basu S, Erlund I, Salminen I, et al. High intakes of vegetables, berries, and apples combined with a high intake of linoleic or oleic only slightly affect markers of lipid peroxidation and lipoprotein metabolism in healthy subjects. Am J Clin Nutr 2002; 76: 950-60.

[18] Briviba K, Schnäbele K, Rechkemmer G. Supplementation of a diet low in carotenoids with tomato or carrot juice does not affect lipid peroxidation in plasma and feces of healthy men. J Nutr 2004; 134: 1081-3.

[19] Dragsted LO, Pedersen A, Hermetter A, Basu S, Hansen M, Haren GR, et al. The 6-a-day study: effects of fruit and vegetables on markers of oxidative stress and antioxidative defense in healthy nonsmokers. Am J Clin Nutr 2004; 79: 1060-72.

[20] Duthie SJ, Jenkinson AM, Crozier A, Mullen W, Pirie L, Kyle $J$, et al. The effects of cranberry juice consumption on antioxidant status and biomarkers relating to heart disease and cancer in healthy human volunteers. Eur J Nutr 2005; 45: 113-22.

http://dx.doi.org/10.1007/s00394-005-0572-9

[21] Pincemail J, Degrune F, Voussure S, Malherbe C, Paquot N, Defraigne JO. Effect of a diet rich in fruits and vegetables on the plasmatic antioxidant rates and of the markers of the oxidative damage. Nutrition clinique et métabolisme.

http://dx.doi.org/10.1016/j.nupar.2007.04.005 
[22] Paterson E, Gordon MH, Niwat C, George TW, Parr L, Waroonphan S, Lovegrove JA. Supplementation with fruit and vegetable soups and beverages increases plasma carotenoid concentrations but does not alter markers of oxidative stress or cardiovascular risk factors. J Nutr 2010; 136: 2849-55.

[23] Polidori MC, Carillo JC, Verde PE, Sies H, Siegrist J, Stahl W. Plasma micronutriment status is improved with 5 daily portions of fruits and vegetables: implications for optimal antioxidant levels. Nutr J 2009; 10: 8-10.

[24] Zino S, Skeaff M, Williams S, Mann J. Randomised controlled trial of effect of fruit and vegetable consumption on plasma concentrations of lipids and antioxidants. BMJ 1997; 314: 1787-91.

http://dx.doi.org/10.1136/bmi.314.7097.1787

[25] Stadler K. Oxidative stress in diabetes. Adv Exp Med Biol 2012; 771: 272-87.

[26] Johnson EL. Glycemic variability in type 2 diabetes mellitus: oxidative stress and macrovascular complications. Adv Exp Med Biol 2012; 771: 139-54.

[27] Omaye ST, Tumbull JD, Sauerlich HE. Selected methods for the determination of ascorbic acid in animal cells, tissues and fluids. Methods Enzymol 1979; 62: 3-11. http://dx.doi.org/10.1016/0076-6879(79)62181-X

[28] Zhao B, Tham SY, Lai MH, Lee LK, Moochhala SM. Simultaneous determination of vitamins $\mathrm{C}, \mathrm{E}$ and betacarotene in human plasma by high-performance liquid chromatography with photodiode-array detection. J Pharm Pharm Sci 2004; 30: 200-4.

[29] Caboni E, Tonelli MG, Lauri $\mathrm{P}$, lacovacci $\mathrm{P}$, Kevers C, Damiano C, Gaspar T. Biochemical aspects of almond microcuttings related to in vitro rooting ability. Biologia Plantarum 1997; 39: 91-7.

http://dx.doi.org/10.1023/A:1000365224324

[30] Richard MJ, Portal B, Meo J, Coudray C, Hadjian A, Favier A. Malondialdehyde kit evaluated for determining plasma and lipoprotein fractions that react with thiobarbituric acid. Clin Chem 1992; 38: 704-9.

[31] Richard MJ, Guiraud P, Meo J, Favier A. High-performance liquid chromatographic separation of malondialdehydethiobarbituric acid adduct in biological materials (plasma and human cells) using a commercially available reagent. J Chromatography 1992; 577: 9-18.

[32] Gueraud F, Peiro G, Bernard H, Alary J, Créminon C, Debrauwer L, et al. Enzyme immunoassay for a urinary metabolite of 4-hydroxynonenal as a marker of lipid peroxidation. Free Radic Biol Med 2006; 40: 54-62. http://dx.doi.org/10.1016/j.freeradbiomed.2005.08.011

[33] Sircar D, Subbaiah PV. Isoprostane measurement in plasma and urine by liquid chromatography-mass spectrometry with onestep sample preparation. Clin Chem 2007; 53: 251-58. http://dx.doi.org/10.1373/clinchem.2006.074989

[34] Youssef H, Groussard C, Pincemail J, Moussa E, Jacob C, Lemoine $\mathrm{S}$, et al. Exercise-induced oxidative stress in overweight adolescent girls: roles of basal insulin resistance and inflammation and oxygen overconsumption. Int J Obesity 2009; 33: 447-55.

http://dx.doi.org/10.1038/ijo.2009.49

[35] Iuliano L, Micheletta F, Natoli S, Ginanni Corradini S, lappelli $\mathrm{M}$, Elisei $\mathrm{W}$, et al. Measurement of oxysterols and alphatocopherol in plasma and tissue samples as indices of oxidant stress status. Anal Biochem 2003; 312: 217-23. http://dx.doi.org/10.1016/S0003-2697(02)00467-0

[36] Larsson $\mathrm{H}$, Bottiger $\mathrm{Y}$, Iuliano L, Diczfalusy U. In vivo interconversion of 7beta-hydroxycholesterol and 7ketocholesterol, potential surrogate markers for oxidative stress. Free Radic Biol Med 2007; 43: 695-701. http://dx.doi.org/10.1016/j.freeradbiomed.2007.04.033
[37] Mackness B, Durrington P, McElduff P, Yarnell J, Azam N, Watt M, Mackness M. Low paraoxonase activity predicts coronary events in the Caerphilly Prospective Study. Circulation 2003; 107: 2775-79.

http://dx.doi.org/10.1161/01.CIR.0000070954.00271.13

[38] Dierckx N, Horvath G, van Gils C, Vertommen J, van de Vliet J, De Leeuw I, Manuel-y-Keenoy B. Oxidative stress status in patients with diabetes mellitus: relationship to diet. Eur J Clin Nutr 2003; 57: 999-08.

http://dx.doi.org/10.1038/sj.ejcn.1601635

[39] Montonen J, Järvinen R, Heliövaara $M$, Reunanen A Aromaa A, Knekt P. Food consumption and the incidence of type II diabetes mellitus. Eur J Clin Nutr 2005; 59: 441-48. http://dx.doi.org/10.1038/sj.ejcn.1602094

[40] Hodge AM, English DR, O'Dea K, Giles GG. Dietary patterns and diabetes incidence in the Melbourne Collaborative Cohort Study. Am J Epidemiol 2007; 165: 603-10. http://dx.doi.org/10.1093/aje/kwk061

[41] Pincemail J, Le Goff C, Charlier C, Gillion P, Cheramy-Bien JP, Van Honacker E, et al. Evaluation biologique du stress oxydant: application en routine clinique. Nutritions \& Endocrinologie. Stress Oxydant 2010; pp. 21-36.

[42] Pincemail J, Defraigne JO, Cheramy - Bien JP, Dardenne N, Donneau AF, Albert A, Labropoulos N, Sakalihasan N. On the potential increase of the oxidative stress status in patients with abdominal aortic aneurysm. Redox Report 2012: 17: 139-44. http://dx.doi.org/10.1179/1351000212Y.0000000012

[43] Rizzo M, Berneis K. Should we measure routinely the LDL peak particle size? Int J Cardiol 2006; 107: 166-70. http://dx.doi.org/10.1016/.ijicard.2005.02.035

Kadiiska MB, Gladen BC, Baird DD, Germolec D, Graham LB, Parker CE, et al. Biomarkers of Oxidative Stress Study II. Are oxidation products of lipids, proteins, and DNA markers of CCl4 poisoning? Free Radical Biol Med 2005; 38: 698-10. http://dx.doi.org/10.1016/j.freeradbiomed.2004.09.017

[45] Devriese S, Huybrechts I, Moreau M, Van Oyen H. Enquête de consommation alimentaire belge 1, 2004. http: //www.iph.fgov.be/nutria.

[46] Promoting fruit and vegetables consumption around the world. www.who.int

[47] Page D, Van Stratum E, Degrou A, Renard CM. Kinetics of temperature increase during tomato processing modulate the bioaccessibility of lycopene. Food Chem 2012; 135: 2462-9. http://dx.doi.org/10.1016/i.foodchem.2012.06.028

[48] Carughi A, Hooper F. Plasma carotenoid levels before and after supplementation with a carotenoid complex. Ann N Y Acad Sci 1993; 691: 244-45.

http://dx.doi.org/10.1111/j.1749-6632.1993.tb26183.x

[49] Hininger I, Chopra M, Thurnham DI, Laporte F, Richard MJ, Favier A, Roussel AM. Effect of increased fruit and vegetable intake on the susceptibility of lipoprotein to oxidation in smokers. Eur J Clin Nutr 1997; 51:601-6.

http://dx.doi.org/10.1038/sj.ejcn.1600451

[50] van den Berg R, van Vliet T, Broekmans WM, Cnubben NH, Vaes WH, Roza $L$, et al. A vegetable-fruit concentrate with high antioxidant capacity has no effect on biomarkers of antioxidant status in male smokers. J Nutr 2001; 131: 171422.

[51] Giammarioli S, Filesi C, Vitale B, Cantagallo A, Dragoni F, Sanzini E. Effect of high intakes of fruit and vegetables on redox status in type 2 onset diabetes: a pilot study. Int $J$ Vitam Nutr Res 2004; 74: 313-20. http://dx.doi.org/10.1024/0300-9831.74.5.313

[52] Chen NG, Azhar S, Abbasi F, Carantoni M, Reaven GM. The relationship between plasma glucose and insulin responses to oral glucose, LDL oxidation, and soluble intercellular 
adhesion molecule-1 in healthy volunteers. http: //www.ncbi.nlm.nih.gov/pubmed/10996356 Atherosclerosis 2000; 152: 203-8.

[53] Roussel AM, Hininger I, Benaraba R, Ziegenfuss TN, Anderson RA. Antioxidant effects of a cinnamon extract in people with impaired fasting glucose that are overweight or obese. J Am Coll Nutr. 2009; 28: 16-21.

http://dx.doi.org/10.1080/07315724.2009.10719756

Received on 28-06-2013 